\title{
FITOTECNIA
}

\section{COMPONENTES DO RENDIMENTO E DESENVOLVIMENTO DO FEIJOEIRO DE PORTE ERETO SOB DIFERENTES DENSIDADES POPULACIONAIS}

\author{
MARCELO MAMORU SHIMADA ${ }^{(2,4)}$; ORIVALDO ARF ${ }^{(3)}$; \\ MARCO EUSTÁQUIO DE SÁ ${ }^{(3)}$
}

\begin{abstract}
RESUMO
O presente trabalho teve por objetivo verificar a influência de densidades populacionais com variação de 133,3 mil a 533,3 mil plantas por hectare, distribuídas em diferentes espaçamentos entrelinhas $(0,30 \mathrm{~m} ; 0,45 \mathrm{~m}$ e $0,60 \mathrm{~m})$ e número de plantas na linha de semeadura $(8,12$ e 16 plantas por metro linear), em componentes do rendimento e no desenvolvimento do feijoeiro (Phaseolus vulgaris L.), cultivares IAC-Carioca Pyatã e IAC-Bico de Ouro, de porte semi-ereto a ereto, cultivados sob irrigação no inverno (maio a agosto de 1995), em Selvíria (MS). Obteve-se uma redução do número de vagens e do número de grãos por planta com o aumento da densidade de semeadura por metro linear, ou com a diminuição do espaçamento entrelinhas. Com esse espaçamento reduzido houve um efeito compensatório no rendimento de grãos, devido ao aumento da população de plantas por área, e à maior massa de sementes. Para os cultivares de porte semi-ereto a ereto obtiveram-se maiores rendimentos em grãos na densidade populacional de 266,7 mil plantas por hectare, utilizando-se o espaçamento de $0,30 \mathrm{~m}$ entrelinhas e oito plantas por metro linear.

Palavras-chave: feijão, cultivares, porte ereto, densidades populacionais, componentes do rendimento.
\end{abstract}

\section{ABSTRACT \\ YIELD COMPONENTS AND CROP GROWTH OF COMMON BEAN UNDER DIFFERENT PLANT DENSITIES}

The present work was carried out in order to verify the influence of different plant densities (133.3 to 533.3 thousand plants.ha $\left.{ }^{-1}\right)$, different row spacings $(0.30 \mathrm{~m}, 0.45 \mathrm{~m}$ and $0.60 \mathrm{~m})$ and number of plants per row $(8,12$ and 16$)$, in the yield components and in the crop growth of Phaseolus vulgaris L., cultivars IAC-Carioca Pyatã and IAC-Bico de Ouro. The experiment was conducted in a Latossol soil, under irrigation during the winter of May-August of 1995, in Selvíria, State of Mato Grosso do Sul, Brazil. A decrease was observed in the number of pods and number of grains per plant with the increase in the plant density or with the decrease in row spacing. Under row spacing decrease, there was an increase in the grain yield and seed mass, due to the larger number of plants ( larger plant population). Two of the cultivars showed larger grain yield under the plant density of 266.7 thousand plants.ha ${ }^{-1}$, and $0.30 \mathrm{~m}$ spacing and 8 plants per meter.

Key words: cultivars, common bean, plant density, yield, components.

(1) Recebido para publicação em 24 de agosto de 1998 e aceito em 19 de abril de 2000.

${ }^{2}$ ) Engenheiro Agrônomo - Faculdade de Engenharia, Universidade Estadual Paulista (UNESP).

(3) Departamento de Fitotecnia, Economia e Sociologia Rural - FE/UNESP, Av. Brasil 56, Caixa Postal 31, 15385-000 Ilha Solteira (SP).

$\left({ }^{4}\right)$ Bolsista da FAPESP. 


\section{INTRODUÇÃO}

A produção nacional de feijão é de cerca de 2,7 milhões de toneladas, com uma área colhida de $4,9 \mathrm{mi}-$ lhões de hectares e produtividade média de 570 kg.ha ${ }^{-1}$, valor considerado baixo se comparado ao potencial produtivo que os cultivares utilizados no País apresentam. Entre os fatores responsáveis pela baixa produtividade de feijão, no Brasil, inclui-se a inadequação das densidades populacionais utilizadas, particularmente para cultivares de feijoeiro semi-ereto a ereto. Nessa cultura têm sido testadas populações de cem mil até um milhão de plantas por hectare, embora tradicionalmente se utilizem cerca de 200 mil plantas por hectare.

No Estado de São Paulo, Almeida et al. (1982), comparando os espaçamentos de $30 \mathrm{~cm}$ a $40 \mathrm{~cm}$ entrelinhas para o cultivar Carioca (tipo III), concluíram que os produtores devem optar pelo espaçamento maior com o objetivo de reduzir os gastos com sementes e facilitar os tratos culturais, tendo em vista que o espaçamento de $30 \mathrm{~cm}$ entrelinhas não apresentou vantagens.

Estudos realizados por FARIA e KRANTZ (1982), no Estado do Paraná, utilizando espaçamentos de $30 \mathrm{~cm}$, $40 \mathrm{~cm}, 50 \mathrm{~cm}$ e $80 \mathrm{~cm}$ entrelinhas e 10 plantas, 15 plantas e 20 plantas por metro linear, com os cultivares Goiano Precoce, Aroana e Carioca, mostraram que, para o cultivar Goiano Precoce (tipo I), as maiores produtividades foram alcançadas nos espaçamentos de $40 \mathrm{~cm}$ e $50 \mathrm{~cm}$ nas entrelinhas, sendo basicamente iguais entre si e pouco superiores às obtidas nos espaçamentos de $30 \mathrm{~cm}$ e $60 \mathrm{~cm}$, em quaisquer das densidades avaliadas. No caso do Aroana (tipo II), as maiores produtividades foram obtidas no espaçamento de $50 \mathrm{~cm}$ nas entrelinhas, sendo, em média, $6 \%$ superiores às produtividades obtidas nos espaçamentos de $40 \mathrm{~cm}$ e $60 \mathrm{~cm}$ e $16 \%$ superiores ao de $80 \mathrm{~cm}$. Comportamento semelhante foi observado no cv Carioca (tipo III), em que o espaçamento de $40 \mathrm{~cm}$ foi mais produtivo que os de $60 \mathrm{~cm}$ e $80 \mathrm{~cm}$, produzindo o de $80 \mathrm{~cm}$ somente $11 \%$ a menos que o de $50 \mathrm{~cm}$. Isso possivelmente se deve ao hábito de crescimento da planta, que, no caso do cultivar Carioca, promove melhor cobertura do solo em relação ao Aroana. No que se refere às densidades utilizadas, os autores concluíram que, em nenhum dos espaçamentos avaliados, a produtividade variou significativamente.

Em Goiânia (GO), Del Peloso (1990) obteve maiores produtividades de feijão irrigado utilizando o espaçamento de $30 \mathrm{~cm}$ para o cultivar EMGOPA 201-Ouro (tipo II) e $40 \mathrm{~cm}$ para o Carioca (tipo III), na densidade de 24 plantas por metro quadrado.
Em alguns estudos mais recentes, as produções obtidas no feijoeiro têm sido superiores quando se utiliza maior número de plantas (aproximadamente 16) por metro linear (ARF et al., 1992; BuZETTI et al., 1992 e ARF et al., 1995) ou menores espaçamentos entrelinhas, de $18 \mathrm{~cm}$ a $30 \mathrm{~cm}$ (Melhorança e Joba, 1991; ArF et al., 1992, FronZA et al., 1994 e ArF et al., 1995). Em tais situações, porém, a realização de tratos culturais, o gasto com sementes e a incidência de problemas fitossanitários são maiores. Entretanto, em muitos casos não se observam diferenças nos rendimentos do feijoeiro em espaçamentos entrelinhas diversos (Almeida et al., 1982) ou sob densidades populacionais distintas (AlCÂNTARA et al., 1991 e LEMOS et al., 1993), independentemente do cultivar utilizado. De acordo com Pereira (1989), em baixa população de plantas a produção individual por planta é maior, embora mais baixa por área. Aumentando-se a população, a produção por planta diminui, havendo, entretanto, um aumento na produção por área. A produção por unidade de área é máxima quando a população é ideal. A partir daí, o decréscimo na produção individual não é compensado pelo aumento na população de plantas.

A busca de novas tecnologias é necessária a fim de se aumentarem os rendimentos da cultura, bem como facilitar os tratos culturais, as operações mecanizadas envolvendo a colheita e melhorar a qualidade do feijão produzido. O melhoramento visando a obtenção de plantas de porte mais ereto, com menor acamamento e maior altura de inserção de vagens, em relação ao solo, atende a esses objetivos. Para os cultivares de porte semi-ereto a ereto ainda são escassas as informações envolvendo densidades populacionais. Assim, o presente trabalho teve como objetivo avaliar a influência de diferentes espaçamentos entrelinhas e número de plantas na linha de semeadura, em componentes do rendimento e no desenvolvimento de cultivares de feijoeiro de porte semiereto a ereto cultivados no inverno, em Selvíria (MS).

\section{MATERIAL E MÉTODOS}

O experimento foi desenvolvido em área experimental pertencente à Faculdade de Engenharia de Ilha Solteira (UNESP), localizada no município de Selvíria (MS), em solo do tipo Latossolo Vermelho-Escuro, epi-eutrófico álico, textura argilosa, de maio a agosto de 1995. Nesse período a precipitação pluvial é muito baixa, chegando a zero em alguns meses.

Os resultados das análises químicas do solo, determinadas na profundidade de $0-20 \mathrm{~cm}$, seguindo a metodologia proposta por RAIJ e QuAGGIO (1983) foram: $P_{\text {resina }}\left(\mathrm{mg} . \mathrm{dm}^{-3}\right)=25 ;$ M.O. $\left(\mathrm{g} \cdot \mathrm{kg}^{-1}\right)=30,7 ; \mathrm{pH}$ 
$\left(\mathrm{CaCl}_{2}\right)=6,3 ; \mathrm{K}, \mathrm{Ca}, \mathrm{Mg}, \mathrm{H}+\mathrm{Al}\left(\mathrm{mmol}_{\mathrm{c}} \cdot \mathrm{dm}^{-3}\right)=2,3$; 39,$0 ; 24,0,17,0$ e 0,0 , respectivamente, e $\mathrm{V}(\%)=79$, em amostras de Latossolo Vermelho-Escuro na profundidade de $0-20 \mathrm{~cm}$.

O delineamento experimental utilizado foi o de blocos ao acaso em esquema fatorial $3 \times 3 \times 2$ com quatro repetições. Foram avaliadas diferentes densidades populacionais variando de 133,3 mil a 533,3 mil plantas por hectare, distribuídas em 18 tratamentos, constituídos pela combinação de diferentes espaçamentos entrelinhas $(0,30 \mathrm{~m} ; 0,45 \mathrm{~m}$ e $0,60 \mathrm{~m})$, número de plantas na linha $(8,12$ e 16 plantas/metro) e cultivares (IAC-Carioca Pyatã e IAC-Bico de Ouro). Os cultivares apresentam plantas de crescimento indeterminado, de guia curta a longa, dependendo do ambiente, porte semi-ereto e ereto, hastes verdes, com e sem pigmentação avermelhada e flores de cor branca. As parcelas foram constituídas de cinco linhas de 6,0 m de comprimento, tendo a área útil três linhas centrais, desprezando-se $0,5 \mathrm{~m}$ em ambas as extremidades de cada linha.

O preparo do solo compreendeu uma aração e duas gradagens, após o que, efetuou-se a sulcação mecânica e a adubação química com $250 \mathrm{~kg} \cdot \mathrm{ha}^{-1}$ da fórmula 4-30-10.

A semeadura realizada em 11/5/1995 foi manual, com o auxílio de réguas de madeira de $6,0 \mathrm{~m}$ de comprimento para a distribuição uniforme das sementes no sulco $\mathrm{O}$ desbaste ocorreu aos oito dias após a emergência, selecionando-se as plantas mais vigorosas e mais bem distribuídas na linha.

A adubação em cobertura foi efetuada aos 25 dias após a emergência das plantas, utilizando-se 50 kg.ha- ${ }^{-1}$ de $\mathrm{N}$, na forma de sulfato de amônio. As irrigações foram realizadas por meio de um sistema convencional por aspersão, de acordo com as necessidades da cultura. Para o controle de plantas daninhas utilizou-se herbicida em pré-plantio, à base de trifluralin (800 g.ha ${ }^{-1}$ do i.a.), por ocasião da segunda gradagem, um pouco antes da semeadura e, posteriormente, realizou-se capina manual, quando necessário.

Na ocasião do florescimento pleno $(50 \%$ das plantas com flores abertas) de cada cultivar determinou-se a quantidade de matéria seca total na parte aérea de 10 plantas de feijoeiro, tomadas ao acaso, em cada parcela experimental, cortadas rente à superfície do solo e após a secagem em estufa de ventilação forçada à temperatura média de $60-70^{\circ} \mathrm{C}$, até atingir massa constante.

O rendimento de grãos foi determinado na área útil da parcela constituída das três linhas centrais, desprezando-se $0,50 \mathrm{~m}$ nas extremidades de cada linha. As plantas foram colhidas manualmente e trilhadas mecanicamente e os grãos pesados, cor- rigindo-se a umidade para $13 \%$. Os dados foram convertidos para kg.ha ${ }^{-1}$. A partir desse material determinou-se a massa de cem sementes. Por ocasião da colheita foram tomadas 10 plantas ao acaso, em cada parcela, para determinação da altura de inserção da primeira vagem, comprimento de vagem, número de vagens por planta, número de grãos por planta e número de grãos por vagem.

As análises estatísticas foram realizadas utilizando-se o Programa SANEST, (ZONTA et al., 1984), e as médias comparadas pelo teste de Tukey a $5 \%$.

\section{RESULTADOS E DISCUSSÃO}

O florescimento pleno e o final do ciclo das plantas foram observados aos 45 e 90 dias e aos 42 e 85 dias, respectivamente, para os cultivares IAC-Bico de Ouro e IAC-Carioca Pyatã.

Os dados de quantidade de matéria seca total da parte aérea, de altura de inserção da primeira vagem, de comprimento de vagem e do número de vagens por planta estão relacionados no quadro 1 , e os de número de grãos por planta, número de grãos por vagem, massa de cem sementes e rendimento médio de grãos, no quadro 2 .

Os resultados de quantidade de matéria seca obtidos no cultivar IAC-Bico de Ouro (3,64 $\left.\mathrm{g} \mathrm{planta}^{-1}\right)$ foram significativamente superiores aos do cultivar IAC-Carioca Pyatã (Quadro 1). Constatou-se que, com o aumento do espaçamento entrelinhas, houve um aumento na quantidade de matéria seca produzi$\mathrm{da}$, ocorrendo o inverso para densidades de plantas cuja produção de matéria seca diminuiu com o aumento do número de plantas na linha, embora não ocorrendo diferença significativa na produção de matéria seca, entre 8 e 12 plantas por metro linear $(3,86$ e 3,43 g.planta ${ }^{-1}$ respectivamente). Isso provavelmente se deve ao fato de ocorrer maior competição entre as plantas por água, luz e nutrientes, nas populações mais adensadas.

Quanto à altura de inserção da primeira vagem, não foi observado nenhum resultado significativo para os tratamentos analisados (cultivares, espaçamentos e densidades de plantas por metro linear). Entretanto é possível observar que há uma tendência para o aumento da altura de inserção da primeira vagem com o incremento do número de plantas por área, seja pela diminuição do espaçamento entrelinhas, seja pelo aumento do número de plantas por metro linear. A observação está de acordo com os resultados alcançados por ALCÂNTARA et al. (1991) e LEMOS et al. (1993), que obtiveram maior altura de inserção de vagens na maior densidade de plantas. Por outro lado, discorda dos resultados obtidos por 
Quadro 1. Valores médios de quantidade de matéria seca total da parte aérea, altura de inserção da primeira vagem, comprimento de vagem e número de vagens por planta. Selvíria (MS), 1995

\begin{tabular}{|c|c|c|c|c|}
\hline Tratamentos & $\begin{array}{c}\text { Quantidade de } \\
\text { Matéria seca total }\end{array}$ & $\begin{array}{c}\text { Altura de inserção } \\
1^{\underline{a}} \text { vagem }\end{array}$ & $\begin{array}{c}\text { Comprimento de } \\
\text { vagem }\end{array}$ & Vagens por planta \\
\hline Cultivar & g.planta ${ }^{-1}$ & $\mathrm{C}$ & 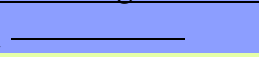 & n. ${ }^{\circ}$ \\
\hline IAC-Bico de Ouro & $3,64 \mathrm{a}$ & 19,03 & $8,67 b$ & $8,27 \mathrm{a}$ \\
\hline IAC Carioca Pyatã & $2,88 \mathrm{~b}$ & 19,60 & 8,99 a & $7,16 \mathrm{~b}$ \\
\hline \multicolumn{5}{|c|}{ Espaçamento entrelinhas (m) } \\
\hline 0,30 & $2,45 c$ & 19,92 & 8,82 & $6,35 b$ \\
\hline 0,45 & $3,38 \mathrm{~b}$ & 19,15 & 8,89 & $7,65 \mathrm{~b}$ \\
\hline 0,60 & $3,95 \mathrm{a}$ & 19,01 & 8,79 & $9,13 \mathrm{a}$ \\
\hline \multicolumn{5}{|c|}{$\begin{array}{l}\text { Densidades de plantas } \\
\left(\text { n. }^{\circ} \text { de plantas. }{ }^{-1} \text { ) }\right.\end{array}$} \\
\hline 8 & $3,86 \mathrm{a}$ & 18,86 & 8,86 & $9,29 a$ \\
\hline 12 & $3,43 \mathrm{a}$ & 19,20 & 8,84 & $7,29 \mathrm{~b}$ \\
\hline 16 & $2,48 b$ & 20,02 & 8,81 & $6,54 \mathrm{~b}$ \\
\hline C.V.(\%) & 22,68 & 11,81 & 4,04 & 24,21 \\
\hline \multicolumn{5}{|l|}{ D.M.S. (Tukey 5\%) } \\
\hline Cultivar & 0,35 & - & 0,17 & 0,88 \\
\hline Espaçamento & 0,51 & - & - & 1,30 \\
\hline Densidade & 0,51 & - & - & 1,30 \\
\hline
\end{tabular}

Médias seguidas da mesma letra, na mesma coluna, não diferem estatisticamente pelo teste de Tukey a 5\%.

Quadro 2. Valores médios de número de grãos por planta, número de grãos por vagem, massa de cem sementes, rendimento médio de grãos. Selvíria (MS), 1995

\begin{tabular}{|c|c|c|c|c|}
\hline Tratamentos & Grãos/planta & Grãos/vagem & $\begin{array}{c}\text { Massa de cem } \\
\text { sementes }\end{array}$ & $\begin{array}{c}\text { Rendimento médio } \\
\text { de grãos }\end{array}$ \\
\hline Cultivar & $\longrightarrow$ & - & $\mathrm{g}$ & kg.ha ${ }^{-1}$ \\
\hline IAC-Bico de Ouro & 39,18 & 4,73 & 22,76 & 1868 a \\
\hline IAC-Carioca Pyatã & 35,24 & 4,95 & 22,83 & $1747 \mathrm{~b}$ \\
\hline \multicolumn{5}{|c|}{ Espaçamento entrelinhas (m) } \\
\hline 0,30 & $30,37 \mathrm{c}$ & 4,79 & 23,39 & 1949 a \\
\hline 0,45 & $36,80 \mathrm{~b}$ & 4,84 & 22,79 & $1753 \mathrm{~b}$ \\
\hline 0,60 & 44,46 a & 4,88 & 22,20 & $1722 b$ \\
\hline \multicolumn{5}{|c|}{ Densidades de plantas $\left(\mathrm{n}^{\mathrm{o}} \mathrm{pl} . \mathrm{m}^{-1}\right)$} \\
\hline 8 & 44,58 a & 4,83 & 22,96 & 1955 a \\
\hline 12 & $35,03 \mathrm{~b}$ & 4,78 & 22,67 & $1717 \mathrm{~b}$ \\
\hline 16 & $32,02 \mathrm{~b}$ & 4,89 & 22,75 & $1749 \mathrm{~b}$ \\
\hline C.V.(\%) & 24,66 & 6,86 & 3,65 & 12,37 \\
\hline \multicolumn{5}{|l|}{ D.M.S. Tukey 5\% } \\
\hline Cultivar & - & - & - & 106,64 \\
\hline Espaçamento & 6,40 & - & - & 157,07 \\
\hline Densidade & 6,40 & - & - & 157,07 \\
\hline
\end{tabular}

Médias seguidas da mesma letra, na mesma coluna, não diferem estatisticamente pelo teste de Tukey a 5\%. 
Melhorança e Joba (1991), que não observaram efeito significativo dos espaçamentos avaliados na altura de inserção da primeira vagem.

Para comprimento de vagem verificou-se que os valores obtidos no cultivar IAC-Carioca Pyatã foram maiores $(8,99 \mathrm{~cm})$ em relação aos do cultivar IAC-Bico de Ouro $(8,67 \mathrm{~cm})$. Não foram observadas diferenças estatísticas entre espaçamentos ou entre densidades, pois essa variável depende basicamente do genótipo, sendo pouco influenciada por fatores ambientais.

Quanto ao número de vagens por planta houve diferenças significativas entre os cultivares, com destaque para o IAC-Bico de Ouro $(8,27)$ em relação ao IAC-Carioca Pyatã $(7,16)$. Além disso, obteve-se maior número de vagens por planta quando se utilizou o espaçamento de $0,60 \mathrm{~m}$ entrelinhas. Com o aumento do número de plantas por metro linear houve uma redução do número de vagens por planta, conforme também observado por ALCÂNTARA et al. (1991), Arf et al. (1992), BuzetTI et al. (1992), LemOs et al. (1993) e ARF et al. (1995). Obtendo resultado semelhante, AlmeidA et al. (1982) recomendaram a utilização de espaçamentos entre $0,50 \mathrm{~m}$ e $0,60 \mathrm{~m}$ entrelinhas, que proporcionam menor gasto com sementes e permitem maior facilidade nos tratos culturais.

Com relação ao número de grãos por planta, houve diferença significativa apenas entre espaçamentos e número de plantas por metro linear, destacando-se os valores obtidos no espaçamento de $0,60 \mathrm{~m}$. O valor obtido no tratamento com oito plantas por metro linear foi significativamente superior aos demais, os quais não diferiram estatisticamente entre si. Tais resultados são concordantes com os obtidos por AlCÂNTARA et al. (1991), BuZEtTI et al. (1992), ArF et al. (1992), Lemos et al. (1993) e ArF et al. (1995).

Quanto ao número de grãos por vagem, observase que houve diferenças significativas entre cultivares e na interação cultivar x densidade (Quadro 2). A diferença entre cultivares era prevista por se tratar de uma característica genética de alta herdabilidade. Com a análise dos resultados de cultivar dentro de densidades (Quadro 3), observa-se que houve efeito significativo apenas na densidade de 12 plantas por metro linear, sendo, em média, esse parâmetro maior no cultivar IAC-Carioca Pyatã. Quanto às densidades dentro de cultivar, observa-se que houve efeito significativo apenas para IAC-Bico de Ouro, em que os valores obtidos na densidade de 16 plantas por metro diferiram significativamente daqueles observados na densidade de 12 plantas por metro, sendo, no entanto, similares aos da densidade de oito plantas por metro. BuzetTI et al. (1992) não observaram alterações no
Quadro 3. Desdobramento das interações significativas da análise de variância referente ao número médio de grãos por vagem. Selvíria (MS), 1995

\begin{tabular}{lccc}
\hline Cultivar & \multicolumn{3}{c}{ Densidades } \\
& (número de plantas por metro linear) \\
\cline { 2 - 4 } & 8 & 12 & 16 \\
\hline IAC-Bico de Ouro & 4,71 a AB & 4,55 b B & 4,92 a A \\
IAC-Carioca Pyatã & 4,96 a A & 5,02 a A & 4,87 a A \\
\hline
\end{tabular}

Médias seguidas da mesma letra, minúscula na coluna e maiúscula na linha, não diferem estatisticamente pelo teste de Tukey a $5 \%$.

D.M.S.: Cultivar dentro de densidade $=0,27$; Densidade dentro de cultivar $=0,33$.

número de grãos por vagem, devido ao do aumento na densidade de plantas.

No que se refere à massa de cem sementes, houve diferenças significativas apenas para espaçamentos e interação espaçamentos x densidades (Quadro 2), estando os desdobramentos apresentados no quadro 4. Analisando-se esses resultados, verifica-se que, para densidades dentro de espaçamentos, houve diferença significativa apenas no espaçamento de $0,60 \mathrm{~m}$. No tratamento com oito plantas por metro linear, os valores de massa de cem sementes diferiram significativamente dos de 12 plantas por metro linear, mas não dos de 16 plantas por metro linear. Para o desdobramento de espaçamentos dentro de densidades observam-se valores significativamente superiores com a utilização de 12 plantas, por metro linear, e do espaçamento de $0,30 \mathrm{~m}$ entrelinhas. Esses resultados diferem dos obtidos por BuzetTI et al. (1992) e ARF et al. (1995), segundo os quais houve uma diminuição da massa de cem sementes com a redução do espaçamento entrelinhas.

Quadro 4. Desdobramento das interações significativas da análise de variância referente à massa de cem sementes $(\mathrm{g})$ de feijão. Selvíria (MS), 1995

\begin{tabular}{lccc} 
Espaçamentos & \multicolumn{3}{c}{$\begin{array}{c}\text { Densidades (número de plantas por } \\
\text { metro linear) }\end{array}$} \\
\cline { 2 - 4 } & \multicolumn{3}{c}{12} \\
\hline $\mathrm{m}$ & $\mathrm{g}$ & 16 \\
0,30 & 23,15 a A & 23,87 a A & 23,15 a A \\
0,45 & 23,17 a A & 22,60 b A & 22,57 a A \\
0,60 & 22,56 a A & 21,52 c B & 22,51 a AB \\
\hline
\end{tabular}

Médias seguidas da mesma letra, minúscula na coluna e maiúscula na linha, não diferem estatisticamente pelo teste de Tukey a $5 \%$.

D.M.S: Espaçamento dentro de densidade $=1,005$; Densidade dentro de espaçamento $=1,005$. 
Quadro 5. Valores de r para correlação simples entre espaçamentos entrelinhas e densidades de plantas na linha e características agronômicas e produtivas do feijoeiro. Selvíria (MS), 1995

\begin{tabular}{lcc} 
& & Valores de $\mathrm{r}$ \\
\cline { 2 - 3 } Variáveis & Espaçamento & Densidades de plantas \\
\hline Altura de inserção de $1^{\mathrm{a}}$ vagem & $-0,93^{* *}$ & $0,96^{* *}$ \\
Matéria seca total & $0,99^{* *}$ & $-097^{* *}$ \\
Comprimento de vagem & $0,29^{\mathrm{ns}}$ & $-0,99^{* *}$ \\
Número de vagens por planta & $0,99^{* *}$ & $-0,95^{* *}$ \\
Número de grãos por planta & $0,99^{* *}$ & $-0,96^{* *}$ \\
Número de grãos por vagem & $0,99^{* *}$ & $0,54^{\mathrm{ns}}$ \\
Massa de cem sementes & $-1,00^{* *}$ & $-0,70^{\mathrm{ns}}$ \\
Produção de grãos & $-0,89^{* *}$ & $-0,79^{*}$ \\
n.s.s não significativo & & \\
$*$ ***significativo ao nível de 5\% e 1\% de probabilidade pelo teste F, respectivamente. &
\end{tabular}

Em relação ao rendimento em grãos (Quadro 2), os valores obtidos no cultivar IAC-Bico de Ouro são significativamente superiores aos do IAC-Carioca Pyatã, concordando com POMPEU et al. (1994). Possivelmente isso se deva ao maior número de vagens e de grãos por planta alcançado pelo cultivar. Observase, também, com o aumento da população de plantas e alterando-se o espaçamento entrelinhas, ter havido aumento no rendimento de grãos. No espaçamento de 0,30 m obtiveram-se os maiores resultados, concordando com Del Peloso (1990), Melhorança e Joba (1991), Arf et al. (1992), FronZA et al. (1994) e Arf et al. (1995). Além disso, esse aumento do rendimento decorrente da diminuição do espaçamento entrelinhas talvez se deva também à obtenção de maiores valores de massa de cem sementes no espaçamento de $0,30 \mathrm{~m}$, se comparado aos de $0,45 \mathrm{~m}$ e $0,60 \mathrm{~m}$. No caso de alterações na densidade de semeadura por metro linear foi observada uma diminuição do rendimento com o aumento do número de plantas na linha, com os melhores resultados obtidos quando se utilizaram oito plantas por metro de linha.

No quadro 5 podem ser observados os valores de $r$ obtidos para as correlações entre espaçamentos entrelinhas e densidade de plantas com as características agronômicas e produtivas dos dois cultivares de feijão utilizados. Pode-se observar que houve correlação negativa e significativa entre espaçamento entrelinhas e altura de inserção da primeira vagem, massa de cem sementes e produção de grãos. Com o aumento do espaçamento houve redução da altura de inserção da primeira vagem, o que pode ser explicado pela maior ramificação lateral das plantas em espaçamento mais amplo e, como conseqüência, porte mais baixo, e o florescimento e a frutificação em menor altura. Com relação à massa de cem sementes, nos espaçamentos maiores observou-se maior produção de vagens por planta e de sementes por vagem, ocorrendo um efeito de diluição, produzindo-se, então, sementes de menor tamanho. Da mesma forma, o aumento da produção individual por planta não foi suficiente para compensar a redução do número de plantas por área nos espaçamentos maiores, ocorrendo então uma diminuição da produção total, em razão do aumento do espaçamento entrelinhas. A redução da produção pelo aumento do espaçamento entrelinhas está de acordo com as observações de DeL Peloso (1990) com relação ao cultivar Engopa 201Ouro (tipo II), e de Faria e Krantz (1982) acerca do cultivar Carioca (tipo III).

Foram obtidas correlações positivas e significativas entre espaçamento entrelinhas e quantidade da matéria seca de plantas, número de vagens e de grãos por planta e número de sementes por vagem, indicando que, com o aumento do espaçamento foi possível obter maior desenvolvimento das plantas. Com isso verificou-se um aumento dos componentes da produção como o número de vagens e de grãos por planta, número de grãos por vagem e, conseqüentemente, maior produção por planta.

Para as densidades de plantas obteve-se correlação negativa e significativa com a quantidade de matéria seca de planta, comprimento de vagem, número de vagens e de grãos por planta, massa de cem sementes e produção de grãos. Assim, com o aumento da densidade populacional, verificou-se redução do desenvolvimento das plantas, do comprimento das vagens e do número de grãos por planta, indicando que, para as plantas com menor quantidade de matéria seca, obteve-se menor produção. Esses resultados corroboram as observações de ALCÂNTARA et al. (1991), Arf et al. (1992), BuzetTI et al. 
(1992) e Lemos et al. (1993), que também verificaram redução do número de vagens por planta com o aumento da densidade populacional, o mesmo ocorrendo em relação ao número de grãos por planta.

\section{CONCLUSÕES}

1. Com o aumento da densidade de semeadura por metro linear ou com a redução do espaçamento entrelinhas, há diminuição do número de vagens e de grãos por planta de feijão.

2. Com a redução do espaçamento entrelinhas, há um efeito compensatório no rendimento de grãos, em virtude do aumento da população de plantas por área e do aumento da massa das sementes.

3. Os maiores rendimentos em grãos do feijoeiro são obtidos na densidade populacional de $266,7 \mathrm{mil}$ plantas por hectare, utilizando-se o espaçamento de 0,30 m entrelinhas e oito plantas por metro linear.

\section{REFERÊNCIAS BIBLIOGRÁFICAS}

ALCÂNTARA, J. dos P.; RAMALHO, M.A.P.; ABREU, A. de F.B.; SANTOS, J.B. dos. Avaliação de cultivares de feijão (Phaseolus vulgaris L.) em diferentes densidades de semeadura e condições de ambiente. Ciência $e$ Prática, Lavras, v.15, n.4, p.375-384, 1991.

ALMEIDA, L. D'A.; BULISANI, E.A.; RONZELI JUNIOR, P., CASTRO, J.L.; VEIGA, A.A. Influência de espaçamentos de plantio na produção do feijoeiro das águas. In: REUNIÃO NACIONAL DE PESQUISA DE FEIJÃO, 2., 1982, Goiânia. Anais. Goiânia: Embrapa CNPAF, 1982. p.112-114.

ARF, O.; BUZETTI, S.; SÁ, M.E.; TOLEDO, A.R.M.; OLIVEIRA, C.A.G.; FUJIWARA, R.H.; ROMEIRO, P.J.M.; GUERREIRO NETO, G. Efeito de diferentes espaçamentos e densidades sobre os componentes produtivos do feijoeiro (Phaseolus vulgaris L.) adubado em função da área e do espaçamento entrelinhas. Cultura Agronômica, Ilha Solteira, v.1, n.1, p.1-10, 1992.

ARF, O.; SÁ, M.E.; BUZETTI, S.; BRANCO, R.B.F.; PAULA, R.C. Efeito de diferentes espaçamentos e densidades em feijoeiro (Phaseolus vulgaris L.) adubado em função da área e da população de plantas. São Paulo: UNESP, 1995. 22p.

BUZETTI, S.; ROMEIRO, P.J.M.; ARF, O.; SÁ, M.E.; GUERREIRO NETO, G. Efeito da adubação nitrogenada em componentes da produção do feijoeiro (Phaseolus vulgaris L.) cultivado em diferentes densidades. Cultura Agronômica, Ilha Solteira, v.1, n.1, p.11-19, 1992.

DEL PELOSO, M.J. Estudo de população de plantas na cultura do feijoeiro de inverno no Estado de Goiás. In: REUNIÃO SOBRE FEIJÃO IRRIGADO (GO, DF, MG, ES, SP, RJ), 1., 1988, Goiânia. Anais. Goiânia: EMBRAPA-CNPAF, 1990. p.85-86. (Documentos, 27)

FARIA, R.T.; KRANTZ, W.M. Determinação dos espaçamentos e densidades adequadas para as culturas de diferentes portes. In: REUNIÃO NACIONAL DE PESQUISA DE FEIJÃO, 1., 1982, Goiânia. Anais. Goiânia: EMBRAPA-CNPAF, 1982. p.118-119.

FRONZA, V.; VIEIRA, C.; CARDOSO, A.A.; CRUZ, C.D.; PEREIRA, P.R.G. Resposta de cultivares de feijão (Phaseolus vulgaris L.) de porte ereto ao efeito de espaçamento entrelinhas e níveis de adubação mineral. Revista Ceres, Viçosa, v.41, p.567-583, 1994.

LEMOS, L.B.; FORNASIERI FILHO, D.; PEDROSO, P.A.C. Comportamento de cultivares de feijoeiro com distintos hábitos de crescimento, em diferentes populações, em semeadura de inverno. Científica, São Paulo, v.21, n.1, p.113-120, 1993.

MELHORANÇA, A.L.; JOBA, I. Efeito do espaçamento entrelinhas sobre o desenvolvimento e produção do feijão (Phaseolus vulgaris L.). Dourados: Empresa Brasileira de Pesquisa Agropecuária, 1991. p.47-49. (EMBRAPA - UEPAE , Documentos, 50)

PEREIRA, A.R. Competição intra-específica entre plantas cultivadas. O Agronômico, Campinas, v.41, n.1, p.5-11. 1989.

POMPEU, S.; RAZERA, L.F.; PEREIRA, J.C.V.N.A.; BORTOLETTO, N.; GALLO, P.B.; MARTINS, A.L.M.;SANTOS, R.R. Cultivares de feijoeiro IAC-Carioca Pyatã e IAC-Bico de Ouro. Campinas: Instituto Agronômico, 1994. p.1-2. (Fôlder)

RAIJ, B. van; QUAGGIO, J.A. Métodos de análise de solos para fins de fertilidade. Campinas: Instituto Agronômico, 1983. 31p. (Boletim Técnico, 81)

ZONTA, E.P.; MACHADO, A.D.; SILVEIRA JUNIOR, P. Sistema de análise estatística para microcomputadores: SANEST. Pelotas: UFPel, 1984. (Registro SEI n. ${ }^{\circ}$ 06606-0 categoria AO). 